This item was submitted to Loughborough's Research Repository by the author.

Items in Figshare are protected by copyright, with all rights reserved, unless otherwise indicated.

\title{
A computational study of stent performance by considering vessel anisotropy and residual stresses
}

PLEASE CITE THE PUBLISHED VERSION

http://dx.doi.org/10.1016/j.msec.2016.01.064

PUBLISHER

(C) Elsevier

VERSION

AM (Accepted Manuscript)

\section{PUBLISHER STATEMENT}

This work is made available according to the conditions of the Creative Commons Attribution-NonCommercialNoDerivatives 4.0 International (CC BY-NC-ND 4.0) licence. Full details of this licence are available at: https://creativecommons.org/licenses/by-nc-nd/4.0/

\section{LICENCE}

CC BY-NC-ND 4.0

\section{REPOSITORY RECORD}

Schiavone, Alessandro, and Liguo Zhao. 2019. "A Computational Study of Stent Performance by Considering Vessel Anisotropy and Residual Stresses”. figshare. https://hdl.handle.net/2134/20270. 


\title{
A Computational Study of Stent Performance by Considering Vessel Anisotropy and Residual Stresses
}

\author{
A. Schiavone and L.G. Zhao* \\ Wolfson School of Mechanical and Manufacturing Engineering \\ Loughborough University, Loughborough, LE11 3TU, UK
}

\begin{abstract}
Finite element simulations of stent deployment were carried out by considering the intrinsic anisotropic behaviour, described by a Holzapfel-Gasser-Ogden (HGO) hyperelastic anisotropic model, of individual artery layers. The model parameters were calibrated against the experimental stress-stretch responses in both circumferential and longitudinal directions. The results showed that stent expansion, system recoiling and stresses in the artery layers were greatly affected by vessel anisotropy. Following deployment, deformation of the stent was also modelled by applying relevant biomechanical forces, i.e. in-plane bending and radial compression, to the stent-artery system, for which the residual stresses generated during deployment were particularly accounted for. Residual stresses were found to have a significant influence on the deformation of the system, resulting in a re-distribution of stresses and a change of the system flexibility. The results were also utilised to interpret the mechanical performance of stent after deployment.
\end{abstract}

Keywords: Stent deployment; vessel anisotropy; finite element; residual stresses; biomechanical forces. 


\section{Introduction}

Stents have been extensively used to treat obstructions of human blood vessels, such as the narrowing of coronary arteries due to plaque accumulation and the formation of aneurysms and blockage caused by anomalous vessel deformation (Fortier et al., 2014). Ideal process of stent deployment requires an expansion which is sufficient to clear vessel obstructions and also induces minimal damage to the vessel walls (Farooq et al., 2011), as in-stent restenosis can be triggered by unsuccessful treatments including vessel over-stretch and injury, incomplete expansion of the stent and fracture of the stent struts. Karimi et al. (2014) assessed arterial vulnerability during stenting and confirmed a risk of damage to the arterial walls, especially when covered with calcified plaque. Computational modelling has been widely used to study the interactions between stents and blood vessels during and after stent deployment, especially finite element (FE) analyses which can model the full process of stent expansion effectively and provide the details of stress distribution within the stent-artery system.

The state of the art in the characterization of arterial wall layers suggests that the fibrereinforced structure of intima, media and adventitia layers, forming the vessel wall, must be taken into account when modelling the deformation of blood vessels. Holzapfel et al. (2000) first showed how the collagenous components of the vessel layers can be modelled by means of fibre orientation to introduce the anisotropic material properties. Their results were in good agreement with the available data for arteries under axial extension, radial inflation and torsion. The same framework has been later employed to model the layer-specific mechanical properties of human coronary arteries (Holzapfel et al., 2005). The study also analysed 13 human nonstenotic left anterior descending (LAD) coronary arteries. The arterial walls were separated into three layers whose mechanical properties were tested in both longitudinal and 
circumferential directions. In all cases, large difference was found between the patients and also the three layers exhibited highly non-linear anisotropic behaviour between the longitudinal and circumferential directions. The computational model showed good agreement with the experimental results, confirming its capability of describing the mechanical behaviour of such materials. However, the implementation of arterial anisotropy in finite element modelling of stent biomechanics is still very limited. Existing work only adopted simplified model to model stent expansion, such as the single-layer anisotropic model used in Auricchio et al. (2013) and the redundant HGO anisotropic model (without the consideration of fibre family) used in Schiavone and Zhao (2015). Consequently, the results were less conclusive and further studies are required to quantitatively elucidate the effects of vessel anisotropy on stent deployment.

Body movements, tissue tethering and blood flow are key factors that induce mechanical loading on arterial branches. When the mechanical stability of the vessel is lost, buckling can occur which generates large bending deformations on the artery (Han et al., 2012). As reviewed by Fortier et al. (2014), implanted stents may undergo a variety of repetitive deformations caused by muscular movements during daily activities such as walking, flexing, respiration and heartbeat. Smouse et al. (2005) studied the stented femoropopliteal arterial segment in 14 limbs of 7 human cadavers. The limbs were flexed to mimic movements such as walking, climbing stairs, sitting and standing. Bending, associated with compression, was observed for arteries behind the knee, and the presence of stents increased the axial rigidity of the vessel, which can cause stent kinking or fracture. Rosenfield et al. (1997) studied stented arterial branches in various vascular sites that were subjected to radial compression, such as six superficial femoral arteries and five hemodialysis conduits. Results showed that restenosis occur as a result of stent compression, and two mechanisms of compression were identified, namely, two point compressive force and complete circumferential encroachment. Despite redilation of the stents, 
restenosis occurred from recurrent compression in most sites. Also, radial compression of the artery can be caused by external pressures due to cardiac contraction or stenosis. Consequently, it is of importance to evaluate stent performance under biomechanical forces, especially bending and radial compression, which has not been well studied yet. In addition, balloonexpandable stents rely on large plastic deformation to resist recoiling and keep the blocked artery open, which inevitably introduces severe residual stresses in the stents. The residual stresses tend to locate at the severely deformed U-bend regions, with magnitude close to the

ultimate tensile strength of the materials (Schiavone et al., 2014) Effect of these residual stresses on stent performance is also considerably lacking in literature.

In this paper, expansion of Xience stent inside an artery with stenosis was simulated using finite element analyses. The work compared the behaviour of stent expansion in an artery described by isotropic and anisotropic hyperelastic models, respectively. After deployment, two major biomechanical movements of the stent-artery system were considered, i.e., bending and radial compression. In particular, the effects of residual stresses on stent deformation were analysed by comparing simulations with and without accounting for the residual stress states. This work highlighted the importance of vessel anisotropy and residual stresses in assessing stent performance during and after deployment.

\section{Methodology}

\subsection{Geometrical models and meshes}

Geometrical model for Xience stent was generated using Abaqus CAE (Abaqus, 2014). The stent was $12 \mathrm{~mm}$ long, with a strut thickness of $80 \mu \mathrm{m}$ and a crimped diameter of $1.58 \mathrm{~mm}$. A tri-folded balloon with a total length of $16 \mathrm{~mm}$ was generated using NX (Siemens PLM Software, UK). The major section of the folded balloon was $14 \mathrm{~mm}$ long, with a diameter of 
$1.24 \mathrm{~mm}$. The ends of the balloon were modelled as a simple circle with a diameter of $0.7 \mathrm{~mm}$ (matching the diameter of the angioplasty catheter), and gradually changed to the fully folded section over a length of $1 \mathrm{~mm}$. The artery was $40 \mathrm{~mm}$ long, with a diameter of $4 \mathrm{~mm}$ and a wall thickness of $1 \mathrm{~mm}$. The wall was divided into three layers, i.e., intima, media and adventitia, with respective thicknesses of $0.27 \mathrm{~mm}, 0.35 \mathrm{~mm}$ and $0.38 \mathrm{~mm}$. The plaque was $10 \mathrm{~mm}$ long and its thickness was gradually increasing from zero to $1 \mathrm{~mm}$ over a distance of $2 \mathrm{~mm}$ at each side, corresponding to a maximum occlusion of $50 \%$.

The stent was meshed using 8-node hexahedral elements with full integration and incompatible modes (C3D8I). This element formulation is suitable for modelling of large bending deformation which occurs during the stent expansion. All struts have four-layer elements through both the thickness and the width, resulting in 227,120 elements for the whole stent. The balloon was meshed using 4-node shell elements with reduced integration (S4R), and the total number of elements was 12,054 . The artery-plaque system was meshed using 8-node hexahedral elements with reduced integration (C3D8R). There are four-layer elements through the thickness of each arterial layer and eight-layer elements through the thickness of the plaque. The total number of elements was 67,392 elements for the artery and 20,736 for the plaque. Mesh sensitivity study confirmed the numerical convergence for the mesh used in this study in terms of diameter change, recoiling and stress distribution for the system. Figure 1 shows the geometry and the mesh for the whole balloon-stent-artery system.

\subsection{Material models}

Elastic-plastic behaviour was assigned to the Xience stent made of the Co-Cr alloy L605. The density, Young's modulus, yield stress and Poisson's ratio for the material are $9.1 \times 10^{-6}$ $\mathrm{Kg} / \mathrm{mm}^{3}, 243 \mathrm{GPa}, 476 \mathrm{MPa}$ and 0.3 , respectively. The hardening behaviour was modelled by 
expressing the increase of yield stress as a function of the plastic strain, obtained from the tensile stress-strain curve. A linear elastic model was adopted for the folded balloon, whose density, Young's modulus and Poisson's ratio are $1.1 \times 10^{-6} \mathrm{Kg} / \mathrm{mm}^{3}, 900 \mathrm{MPa}$ and 0.3 , respectively. The hypocellular plaque was modelled as an isotropic hyperelastic material using the Ogden strain energy potential, with parameters given in Zahedmanesh et al. (2010).

The Holzapfel-Gasser-Ogden (HGO) formulation was used to model the anisotropic behaviour of the arterial layers, with strain energy potential described by

$$
\begin{aligned}
& W=C_{10}\left(I_{1}-3\right)+\frac{k_{1}}{2 k_{2}}\left[\exp \left(k_{2}\langle E\rangle^{2}\right)-1\right]+\frac{1}{D}\left(\frac{(J)^{2}-1}{2}-\ln J\right), \\
& E=\kappa\left(I_{1}-3\right)+(1-3 \kappa)\left[I_{4}-1\right]
\end{aligned}
$$

where $C_{10}, D, k_{1}, k_{2}$ and $\kappa$ are material parameters, $\mathrm{I}_{4}$ is the invariant of Cauchy-Green deformation tensor and $E$ represents the deformation of the fibre families. The Macauley bracket is indicated by the operator $<>$. In this model, two families of fibres were considered, and $\gamma$ is the angle between the mean directions of the two families of fibres. The HGO model for the three arterial layers was calibrated against the average stress-strain behaviour measured for 13 patients in Holzapfel et al. (2005). The calibrated parameters for the HGO model are shown in Table 1. Figure 2 plots the in the circumferential and longitudinal stress-stretch responses of the HGO model for the intima, media and adventitia layers which are in very good agreement with the experimental data (Holzapfel et al., 2005). The radial stress-strain responses were also given in Figure 2 which further confirmed the anisotropic behaviour of the vessel layers. 


\subsection{Finite element procedure}

Abaqus explicit solver was used for the simulations (Abaqus, 2014), with automatic time increment (on the order of $10^{-8} \mathrm{~s}$ ) and semi-automatic mass scaling (with a factor of 5). The ends of the artery were fully constrained to avoid rigid body movements of the system. The ends of the balloon were also fully constrained to reflect its fixation to the catheter. The artery layers and the artery-plaque interface were considered as perfectly bonded. The interaction between the stent, the balloon and the artery was modelled using hard contact formulation. A friction coefficient of 0.25 (Ju et al., 2008) was assigned for the contact surfaces to avoid sliding of the stent in the longitudinal direction. To verify the quasi-static condition, the internal and kinetic energies were monitored for the whole simulation process. In all simulations, the kinetic energy was found to be always less than $5 \%$ of the internal energy, confirming the validity of the quasi-static conditions (Gastaldi et al., 2010).

The stent deployment was divided into two steps, i.e., the inflation and deflation steps. The step time was chosen to 0.1 second for both inflation and deflation. Inner pressure was applied to the folded balloon, increasing linearly to $1.4 \mathrm{MPa}$ in the inflation step and decreasing linearly to zero in the deflation step. The diameter change against pressure was monitored for the middle and the two ends of the stent, in order to capture the expansion behaviour and calculate the dogboning and recoiling effects.

\subsection{Deformation under biomechanical forces}

After the deployment, system deformation was modelled by considering two major biomechanical forces, i.e., bending and radial compression, generated from artery movements. For all cases, the simulations were carried out using the HGO anisotropic model for the arterial 
layers, with and without accounting for the residual stresses in the stent-artery-plaque system induced by the stent deployment. Bending was modelled by imposing $5 \mathrm{~mm}$ of displacement in the Y-direction to all the nodes in the middle cross-section of the artery-plaque system, as illustrated in Figure 3a. Both ends of the artery were kept fully constrained, and the stresses on the stent and the artery-plaque system were monitored during the simulations. As illustrated in Figure $3 \mathrm{~b}$, radial compression was simulated by applying a linearly increasing pressure of 0.2 MPa to the outer surface of the artery, over a length of $20 \mathrm{~mm}$ in the middle part. In this case, the ends of the artery were fixed in all directions, similar to the bending simulations. The diameter change against pressure was monitored at the centre and the two ends of the plaque's inner surface, along with stresses in the stent-artery-plaque system.

\section{Results}

\subsection{Effect of vessel anisotropy on stent deployment}

The expansion behaviour of the stent-artery system, simulated using the isotropic and anisotropic arterial models, is compared in Figure 4 by plotting the change of stent outer diameter against the inflating pressure. The isotropic model of the arterial layers was described by an Ogden hyperelastic strain energy potential, with parameters given in Zahedmanesh et al. (2010). The response of the isotropic model can be seen in Figure 2, which matches the circumferential stress-stretch response for each artery layer. Before the expansion reaches saturation, the rate of artery dilation was almost identical for both arterial models. However, for the anisotropic model, the expansion saturation started at a diameter of $3.56 \mathrm{~mm}$, whilst for isotropic material behaviour, it started at a diameter of $3.90 \mathrm{~mm}$. The difference in stent expansion was also seen at peak pressure (1.4 MPa), i.e., a diameter of $3.85 \mathrm{~mm}$ for isotropic model versus a diameter of $4.08 \mathrm{~mm}$ for anisotropic model. After the deflation, the recoiling (Figure 4b) was higher for the isotropic model than that for the anisotropic one, with a value 
of $13.0 \%$ and $10.6 \%$, respectively. The final diameter achieved by the stent expansion was 3.56 $\mathrm{mm}$ for the isotropic model and $3.45 \mathrm{~mm}$ for the anisotropic model, which are comparable. Figure $4 \mathrm{~b}$ also shows the dogboning effect, which was similar for both cases $(\sim 22 \%)$.

\subsection{Residual stresses generated during stent deployment}

The von Mises stress contour on the stent after deployment is compared in Figure 5a for anisotropic and isotropic artery models. The stress distribution was similar in both cases, with maximum stresses located at the U-bends of the stent. After deflation, the maximum von Mises stress was settled at $995 \mathrm{MPa}$ and $1005 \mathrm{MPa}$ for anisotropic and isotropic artery models, respectively. Figure 5b shows the von Mises stresses on the plaque at the end of deployment, with a magnitude of $1.83 \mathrm{MPa}$ and $2.44 \mathrm{MPa}$ for anisotropic and isotropic arterial models, respectively, and similar stress distribution can be seen for both cases. The stress contour in the arterial wall is shown in Figure 5c. In both cases, the peak stress was found in the intimal layer, localised towards the ends of the diseased section due to the stent dogboning. The peak von Mises stress in the intima layer was found to be $0.71 \mathrm{MPa}$ for the anisotropic material behaviour and $0.23 \mathrm{MPa}$ the isotropic one. It should be noted that the geometry of the Xience stent is not symmetrical in the longitudinal (or axial) direction, due to the selectively positioned connector struts. For this reason, the stiffness of the stent is varying along the axial direction. The left end is stiffer than the right end, which results in asymmetric stress distribution on the artery (see Figures 5, 7 and 9).

\subsection{Effect of residual stresses on deformation under bending}

The residual stresses on the artery and stent caused by the deployment mainly affected the vessel wall during the bending deformation of the system. On the stent (Figure 6a), the maximum von Mises stress was comparable before and after the bending, with a value of 995 
$\mathrm{MPa}$ and $992 \mathrm{MPa}$, respectively. The hypocellular plaque (Figure 7a) exhibited stress relaxation during the bending, and the peak von Mises stress, localised in the middle of the inner surface, decreased from 1.83 MPa (Figure 5b) to 1.05 MPa (Figure 7a). The stress level on the intima layer significantly increased during the bending process. The magnitude of peak von Mises stress after bending was $1.30 \mathrm{MPa}$ on the inner surface of the layer (Figure $7 \mathrm{~b}$ ), compared to $0.71 \mathrm{MPa}$ (Figure 5c) after deployment. When the residual stresses were not included in the simulation, high levels of stresses (629 MPa) were found on the connector struts in the middle region of the stent (Figure 6b), associated with severe bending of the connector struts. When the residual stresses were included, the same stent strut showed a maximum von Mises stress of only $312 \mathrm{MPa}$ (Figure 6b). Also, the stress was only $0.08 \mathrm{MPa}$ on the plaque and 0.60 MPa in the intima layer (Figure 7).

\subsection{Effect of residual stresses on deformation under radial compression}

Under radial compression, the diameter change against pressure was monitored at three points of the inner surface, marked as $\mathrm{A}, \mathrm{B}$ and $\mathrm{C}$ in Figure $3 \mathrm{~b}$, of the plaque and plotted in Figure 8. The diameter differed at the three points due to the circumferential variation of stent structure, with a weaker strength at Point $\mathrm{C}$ when compared to Points $\mathrm{A}$ and $\mathrm{B}$ (Figure 8a to 8c). The collapse of the artery was observed in both cases at point $\mathrm{C}$ when the pressure reached a value of $0.2 \mathrm{MPa}$. At Point A, the final diameter was similar for the simulations with and without residual stresses, with a value of $2.19 \mathrm{~mm}$ and $2.27 \mathrm{~mm}$ (Figure $8 \mathrm{~d}$ ), respectively. There was a difference for Point B, with a value of $1.91 \mathrm{~mm}$ and $2.15 \mathrm{~mm}$ (Figure $8 \mathrm{~d}$ ) for the simulations with and without residual stresses, respectively. For point $\mathrm{C}$, the stent-artery system collapsed more when the residual stress state was accounted for. Specifically, the lumen diameter was reduced to only $1.22 \mathrm{~mm}$ after the application of pressure, compared to $1.89 \mathrm{~mm}$ obtained from the simulation which neglected the residual stress state (Figure 8d). 
Stress distributions after radial compression are shown in Figure 9 for the stent-artery system, with and without residual stresses. For the simulation which accounted for the residual stress state, an increase of stresses on the stent was found due to the compression, i.e., increased from $995 \mathrm{MPa}$ before the application of pressure to $1004 \mathrm{MPa}$ after the application of pressure. This is almost equal to the ultimate tensile strength of Co-Cr L605, suggesting the risk of device failure. Under compression, there was a considerable increase of peak von Mises stress levels in the intimal layer, i.e. from 0.71 MPa (Figure 5c) to 5.17 MPa (Figure 9b). The peak value was far above the strength of the intima layer in the longitudinal direction, which is reported to be $0.94 \mathrm{MPa}$ (Khamdaengyodtai et al., 2012). Also, the peak stresses were shifted towards the ends of the artery, where the tissue had more freedom to deform due to the absence of the stent. Without residual stresses, the stress on the stent had a maximum level of $835 \mathrm{MPa}$ which is lower than that (1004 MPa) with residual stresses. The stress on the artery was mainly concentrated in the intima layer, with a peak value of 4.42 MPa. As seen in Figure 9, stress distribution was very similar for simulations with and without residual stresses.

\section{Discussions}

\subsection{Vessel anisotropy and hyperelastic behaviour}

Results of the stent deployment highlight the importance of the anisotropic behaviour of the artery. The expansion exhibited earlier saturation state when considering the anisotropy of the artery. However, the finally achieved diameter was comparable to that for isotropic model due to the reduced recoiling. The recoiling of the plaque-artery system imposed additional compression on the stent, leading to increased levels of stresses on the stent after balloon deflation when compared to those at peak inflating pressure. Consequently, lower stress levels were found on the stent struts for anisotropic vessel model. Vessel anisotropy also affects the 
stress levels on the artery-plaque system. Despite the constitutive model of the plaque was identical in both simulations, the stress on the plaque was higher when neglecting the anisotropy of the arterial layers. However, the intima layer exhibited a considerable increase of stress levels when considering vessel anisotropy, which is caused by its much higher stiffness in the longitudinal direction.

The results presented above were obtained based on the mean stress-stretch response of the vessel layers tested for 13 patients in Holzapfel et al. (2005). The data had a large scatter and showed significant variation in arterial stiffness among the patients chosen. Arterial stiffening can be associated with ageing, due to the degeneration of the elastin fibres. Other clinical factors can also affect the stiffness of the arteries, such as rapid weight gain, obesity and type II diabetes (Payne et al., 2010). Furthermore, inflammation, calcification, endothelial dysfunction, vascular growth and remodelling also affect the mechanical behaviour of arterial layers. In the study of Holzapfel et al. (2005), specimens were gathered from thirteen different patients ranging between 54 and 80 years of age. Results showed that the stiffness of the arterial tissues was very different between the patients. To assess how arterial stiffening can affect the stent deployment, stent expansion was simulated using patient specific data, i.e. the stressstretch response for patients VI and IX tested in Holzapfel et al. (2005). The two specific cases represented the stiffest and the softest arteries, especially the intimal layer, among the 13 patients. The stress-stretch curves of the two patient specific cases, along with the mean behaviour (averaged over all the patients), are shown in Figure 10, where the simulations refer to HGO model whose parameters were fitted against the test data for patient VI and IX (Table 2). 
Figure 11 shows the diameter change against pressure for the two specific patients, in comparison with that obtained from the mean artery behaviour. The expansion saturation was achieved at a larger diameter for patient VI, with a maximum diameter of $4.10 \mathrm{~mm}$ at peak pressure and a final diameter of $3.49 \mathrm{~mm}$ after deflation. However, for patient IX the maximum expansion was only of $2.75 \mathrm{~mm}$ and the final diameter was just $2.59 \mathrm{~mm}$, indicating a failure in stent expansion due to the high stiffness of the vessel. System recoiling was found increased significantly with the increasing stiffness of the arterial layers, from $5.8 \%$ for patient IX (stiff artery) to $13 \%$ for patient VI (soft artery). Dogboning was also affected by the arterial stiffness, i.e. $19 \%$ for patient VI and $58 \%$ for patient IX, compared to $10.6 \%$ obtained based on the mean behaviour (Figure 4b).

The von Mises stress on the stent after deployment are shown in Figure 12a for patients VI and IX. The stress had a maximum magnitude of $1006 \mathrm{MPa}$ for patient VI, compared to $944 \mathrm{MPa}$ for patient IX and $995 \mathrm{MPa}$ for the mean behaviour. On the plaque (Figure 12b, von Mises stress), the stress was also found increased for patient VI, with a peak value of $2.53 \mathrm{MPa}$, compared to $0.84 \mathrm{MPa}$ for patient IX and 1.83 MPa (Figure 5b) for the mean behaviour. For the arterial wall (Figure 12c), the peak von Mises stress was found in the intimal layer in all cases, with values of $0.13 \mathrm{MPa}$ and 2.20 MPa for patient VI and patient IX, respectively (compared to $0.71 \mathrm{MPa}$ for the mean artery behaviour in Figure 5c).

These results show that the stiffness of the arterial layers plays a major role on the stent expansion and highly affect the diameter achieved by the end of deflation. Patient IX with high arterial stiffness may represent a failure case for the stent deployment as the stenosis was only cured by $15 \%$. The stresses on the stent and the plaque system are also strongly affected by the 
arterial stiffness: the stress on the artery was found considerably higher in arteries with higher stiffness (i.e. patient IX), suggesting the high risk of arterial damage and rupture.

\subsection{Effects of residual stresses on deformation}

This work also studied the effects of residual stress on the deformation of stented artery system when subjected to biomechanical forces after deployment. For bending, residual stresses affect the deformation and the final stress state of the stent-artery system significantly. When considering the residual stresses, the deformation on the connector struts was not as severe as that without considering the residual stress state (Figure 8). The high residual stresses presented on the U-bend struts after deployment indicated that the stent is in the plastic deformation regime, which allows the U-bends to deform more easily when under further loading due to the lower modulus in the plastic hardening stage. On the contrary, when the residual stress state is neglected, the bending of the stent is mainly carried by the connector struts. The bending appears to have little impact on the stress state in the plaque, but strongly affects the stress state in the intima layer of the artery wall. By considering the residual stresses on the artery, the stress in the intima layer caused by bending was re-distributed significantly and also had higher magnitudes, which can affect the prediction of tissue damage.

For radial compression, the anisotropy of the artery affects the system deformation considerably, since the stress-strain response of the intima and adventitia layers of the artery in the axial direction is much stiffer compared to the circumferential behaviour (Figure 2). The collapse of the stent-artery system became more prominent when accounting for the residual stress state. Also, the stiffness of the system varied in the axial direction, with the left side of the artery being less resistant to radial compression due to its relatively higher structural strength. Stent collapse also affected the stress state on the intima layer, because it allowed the 
artery to be stretched uniformly in the longitudinal direction, leading to reduced stress level. The overall stress level of the system tended to increase for the simulation with residual stresses, due to the collapse of the stent. For the simulation without residual stress, lower stresses in the artery-plaque system were obtained due to the reduced level of deformation associated with higher stiffness of the stent in the radial direction.

\subsection{Limitations of current work}

In this work, residual stresses generated from crimping were not considered, which requires a simulation of the full process of stent crimping. Residual micro-stresses were observed in stents after the crimping process by Möller et al. (2000), which increased even further after the balloon expansion due to tension. To this purpose, we also carried out some preliminary work to simulate the crimping process of Xience stent. The residual stresses were shown to be on the level of $750 \mathrm{MPa}$, which is comparable to the residual stresses generated out of stent deployment. It is believed that these residual stresses will affect the stent expansion during subsequent stent deployment and further work is undergoing to quantify such effects numerically.

In our paper, the stresses in the artery-plaque system were found to be in the range of $1 \sim 3 \mathrm{MPa}$, which are generally beyond the ultimate tensile stress values for tissue layers as reported in Holzapfel et al. (2005). Consequently, tissue damage needs to be considered in the HGO model at such high stress levels, which might reduce the stent recoiling upon balloon deflation due to the irreversible deformation associated with tissue damage. A considerable amount of additional work is required to simulate tissue damage and will be considered in our future studies. In addition, the plaque can be modelled as hypocellular, cellular or calcified plaque depending on its composition. Calcified plaque is more resistant to stretch than hypocellular 
and cellular plaques, and prohibits stent expansion considerably (Schiavone et al., 2014). Again such effects were only evaluated for isotropic arterial model, and further work is required to quantify the effect of plaque composition for anisotropic artery model.

The blood pressure was neglected for all the simulations in this study. Blood pressure is believed to affect the simulation results, especially the post-deployment deformation of the stented system under biomechanical forces (bending and compression). In order to understand such effect, the simulations need to be run by applying a pressure on the inner surface of the blood vessel. This will involve a significant amount of additional work and is beyond the scope of the current paper. And we plan to study this in our future work.

\section{Conclusions}

Finite element simulation of stent deployment was carried out using an anisotropic model for the artery, consisting of three individual tissue layers, i.e., intima, media and adventitia. Each layer was modelled as a hyperelastic anisotropic material described by the Holzapfel-GasserOgden (HGO) model. The results showed that, at the peak pressure, stent expansion obtained using the anisotropic model was reduced when compared to that obtained using the isotropic model. However, after deflation, the finally achieved diameter for the anisotropic model is comparable to that for the isotropic model, due to the reduction in recoiling for the anisotropic model. Also, the anisotropic model generated higher levels of stress in the artery layers than the isotropic model. Furthermore, care should be taken to treat patients with significant arterial stiffening as it can lead to failure of the arterial expansion and risk of damage. Following deployment, deformation of the system was also modelled by applying relevant biomechanical forces, such as bending and radial compression. Residual stresses generated out of deployment process were found to have an influence on the deformation of the system, resulting in re- 
distribution of stresses and change of flexibility of the system. In summary, it is strongly recommended to take into account the vessel anisotropy and residual stresses to model expansion and deformation of the stent-artery system.

\section{Acknowledgement}

The research leading to these results received funding from the European Union Seventh Framework Programme (FP7/2007-2013) under grant agreement No. PIRSES-GA-2013610547 TAMER.

\section{References}

ABAQUS, Version 6.13, 2013. Dassault Systèmes, Vélizy-Villacoublay, France.

F Auricchio, M Conti, A Ferrara, S Morganti and A Reali. 2013. "Patient-specific finite element analysis of carotid artery stenting: a focus on vessel modeling." International Journal for Numerical Methods in Biomedical Engineering 29 (6):645-64.

V Farooq, BD Gogas and PW Serruys. 2011. "Restenosis delineating the numerous causes of drug-eluting stent restenosis." Circulation: Cardiovascular Interventions 4 (2):195-205.

A Fortier, V Gullapalli and RA Mirshams. 2014. "Review of biomechanical studies of arteries and their effect on stent performance." IJC Heart \& Vessels 4:12-8.

D Gastaldi, S Morlacchi, R Nichetti, C Capelli, G Dubini, L Petrini and F Migliavacca. 2010. "Modelling of the provisional side-branch stenting approach for the treatment of atherosclerotic coronary bifurcations: effects of stent positioning." Biomechanics and Modeling in Mechanobiology 9 (5):551-61.

H-C Han, JKW Chesnutt, JR Garcia, Q Liu and Q Wen. 2013. "Artery buckling: new phenotypes, models, and applications." Annals of Biomedical engineering 41 (7):1399410. 
GA Holzapfel, TC Gasser, and RW Ogden. 2000. "A new constitutive framework for arterial wall mechanics and a comparative study of material models." Journal of Elasticity and the Physical Science of Solids 61 (1-3):1-48.

GA Holzapfel, G Sommer, TC Gasser and P Regitnig. 2005. "Determination of layer-specific mechanical properties of human coronary arteries with nonatherosclerotic intimal thickening and related constitutive modeling." American Journal of Physiology-Heart and Circulatory Physiology 289 (5):H2048-H58.

SM Imani, AM Goudarzi, SE Ghasemi, A Kalani and J Mahdinejad. 2014. "Analysis of the stent expansion in a stenosed artery using finite element method: Application to stent versus stent study." Proceedings of the Institution of Mechanical Engineers, Part H: Journal of Engineering in Medicine 228 (10):996-1004.

F Ju, Z Xia and K Sasaki. 2008. "On the finite element modelling of balloon-expandable stents." Journal of the Mechanical Behavior of Biomedical Materials 1 (1):86-95.

VA Kamenskiy, II Pipinos, AY Dzenis, J Bikhchandani, KP Gupta, N Philips, SAJ Kazmi and NJ MacTaggart. 2013. "Effects of carotid artery stenting on arterial geometry." Journal of the American College of Surgeons 217 (2):251-62.

A Karimi, M Navidbakhsh and R Razaghi. 2014. "A finite element study of balloon expandable stent for plaque and arterial wall vulnerability assessment." Journal of Applied Physics 116:044701.

D Möller, W Reimers, A Pyzalla and A Fischer. 2001. "Residual stresses in coronary artery stents." Journal of Biomedical Materials Research 58 (1):69-74.

RA Payne, IB Wilkinson and DJ Webb. 2010. "Arterial stiffness and hypertension emerging concepts." Hypertension 55 (1):9-14. 
K Rosenfield, R Schainfeld, A Pieczek, L Haley and JM Isner. 1997. "Restenosis of endovascular stents from stent compression." Journal of the American College of Cardiology 29 (2):328-38.

A Schiavone, LG Zhao, and AA Abdel-Wahab. 2014. "Effects of material, coating, design and plaque composition on stent deployment inside a stenotic artery - finite element simulation." Materials Science and Engineering: C 42:479-88.

HB Smouse, A Nikanorov, and D LaFlash. 2005. "Biomechanical forces in the femoropopliteal arterial segment." Endovascular Today 4 (6):60-6.

H Zahedmanesh and C Lally. 2009. "Determination of the influence of stent strut thickness using the finite element method: implications for vascular injury and in-stent restenosis." Medical \& Biological Engineering \& Computing 47 (4):385-93. 


\section{Tables}

Table 1. HGO model parameters fitted for the mean behaviour of each arterial layer (Holzapfel et al., 2005).

Table 2. HGO model parameters for the arterial layers fitted for patients VI and IX (Holzapfel et al., 2005). 


\section{Figure Captions}

Figure 1. Finite element mesh for the stent-artery-balloon system.

Figure 2. Stress-stretch response simulated using the HGO model, in comparison with experimental results given in Holzapfel et al. (2005).

Figure 3. Illustration of constraints and loading conditions for (a) bending and (b) radial compression.

Figure 4. (a) Diameter change against pressure and (b) recoiling and dogboning effects for Xience stent deployed in the artery modelled with anisotropic and isotropic hyperelastic strain energy potentials.

Figure 5. Contours plots of von Mises stress for (a) stent, (b) plaque and (c) artery after deployment of Xience stent, comparison between isotropic and anisotropic arterial models.

Figure 6. Comparison of deformation and von Mises stress for the stent simulated (a) with and (b) without considering residual stresses.

Figure 7. Contour plots of von Mises stress (a) on the plaque and (b) in the vessel layers after bending simulated with and without residual stresses. 
Figure 8. Diameter change against pressure during radial compression for (a) point A, (b) point B and (c) point C; (d) Comparison of collapsed diameters at maximum pressure (0.2 MPa) for the three points.

Figure 9. Contour plots of von Mises stress for (a) the stent and (b) the arterial wall at an applied pressure of $0.2 \mathrm{MPa}$ obtained from simulations with and without residual stresses.

Figure 10. Stress-stretch response (both HGO model and experimental data) for patient VI and patient IX, in comparison with the average material behaviour.

Figure 11. (a) Stent expansion and (b) recoiling and dogboning effects for the two specific patients, in comparison with those obtained from the mean artery behaviour.

Figure 12. Contour plots of von Mises stress for (a) stent, (b) plaque and (c) arterial layers after deployment of Xience stent in arteries with patient specific behaviour (Holzapfel et al., 2005). 


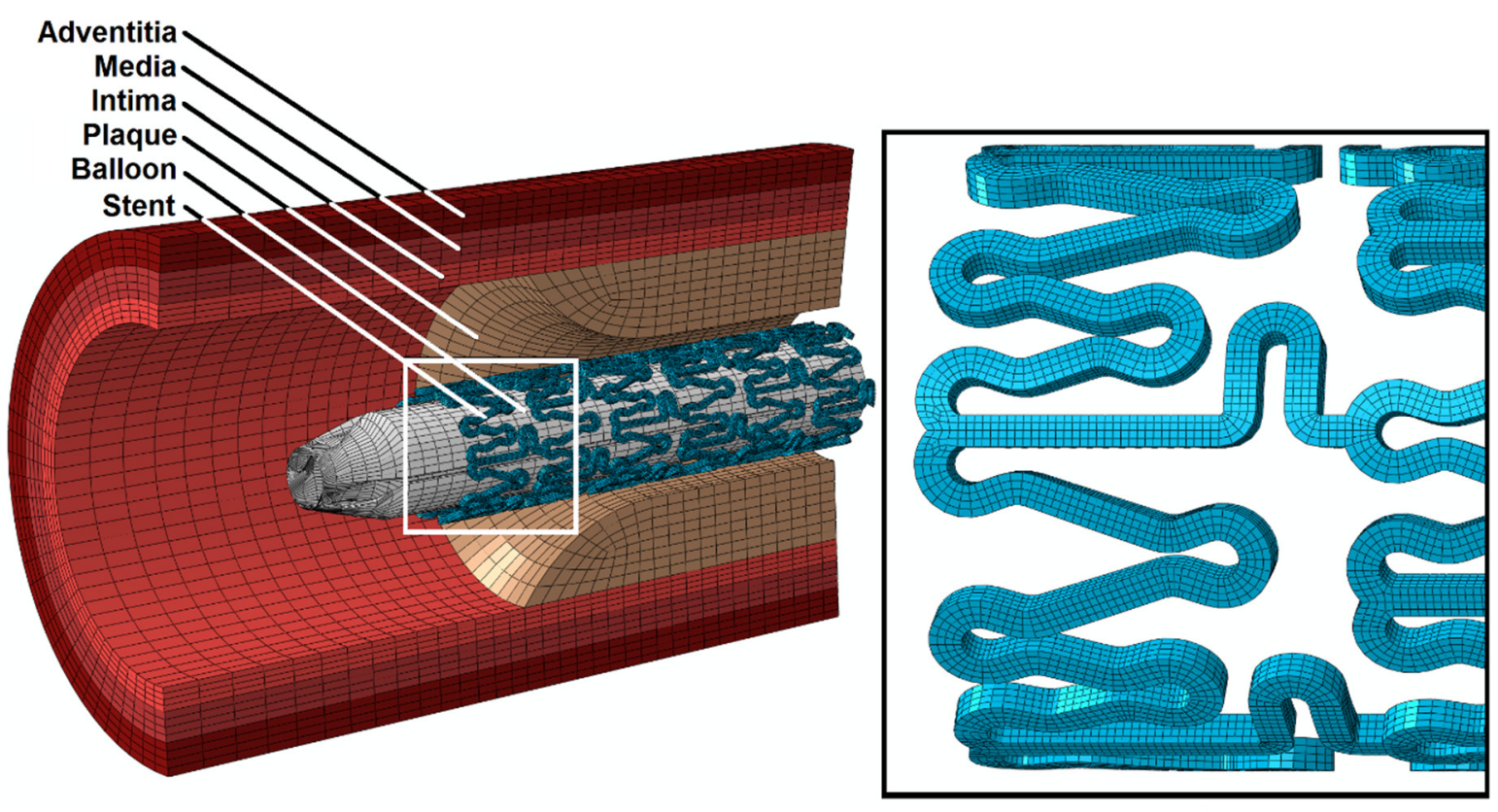

Figure 1. Finite element mesh for the stent-artery-balloon system. 

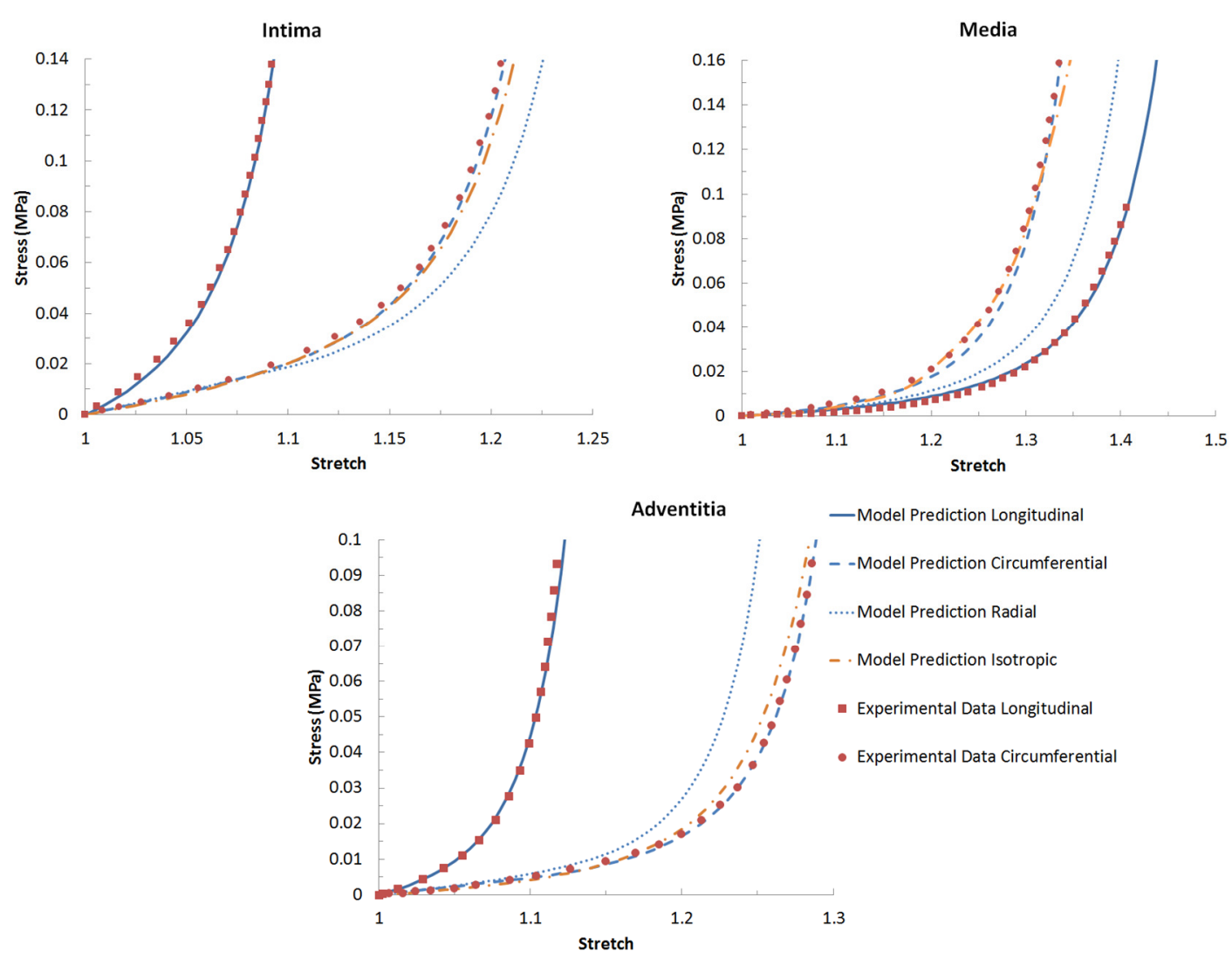

Figure 2. Stress-stretch response simulated using the HGO model, in comparison with experimental results given in Holzapfel et al. (2005). 
(a)
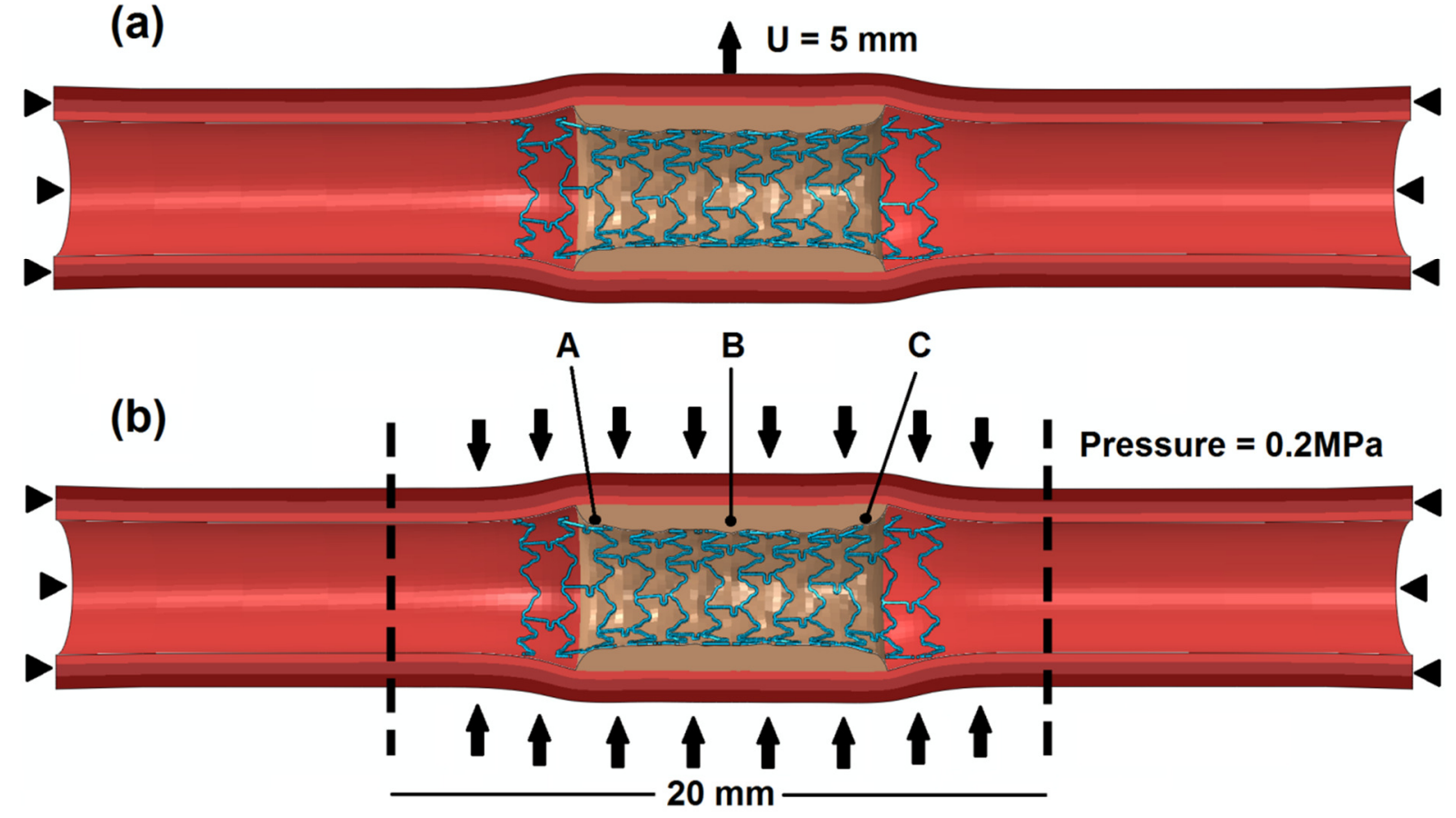

Figure 3. Illustration of constraints and loading conditions for (a) bending and (b) radial compression. 


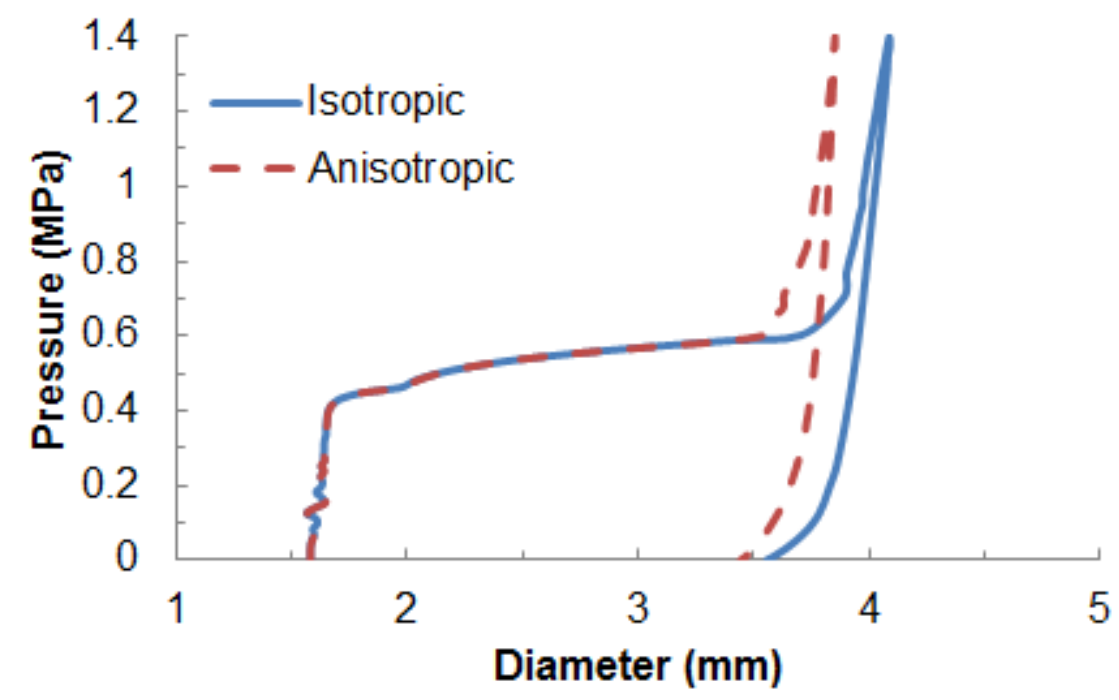

(a)

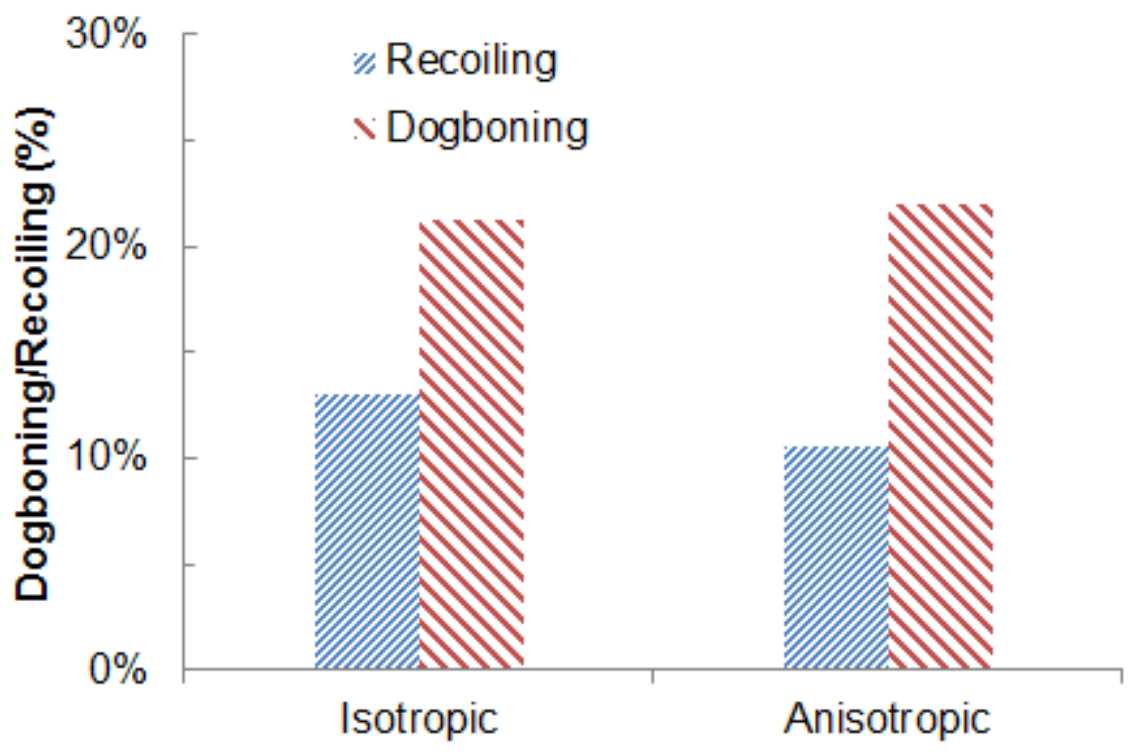

(b)

Figure 4. (a) Diameter change against pressure and (b) recoiling and dogboning effects for Xience stent deployed in the artery modelled with anisotropic and isotropic hyperelastic strain energy potentials. 
(a)

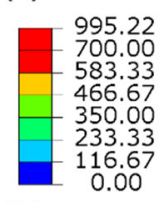

Anisotropic

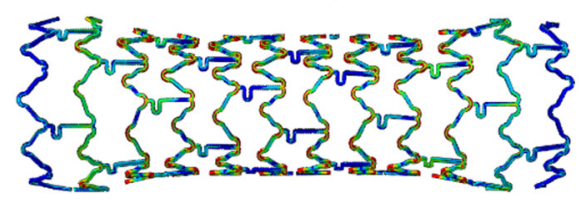

(b)
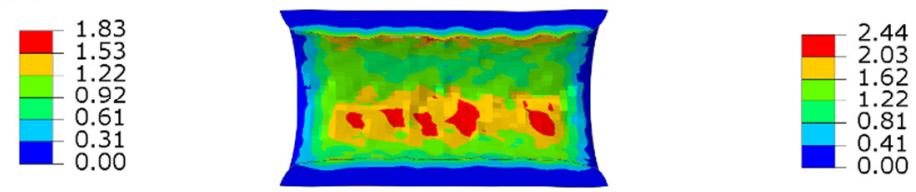

(c)
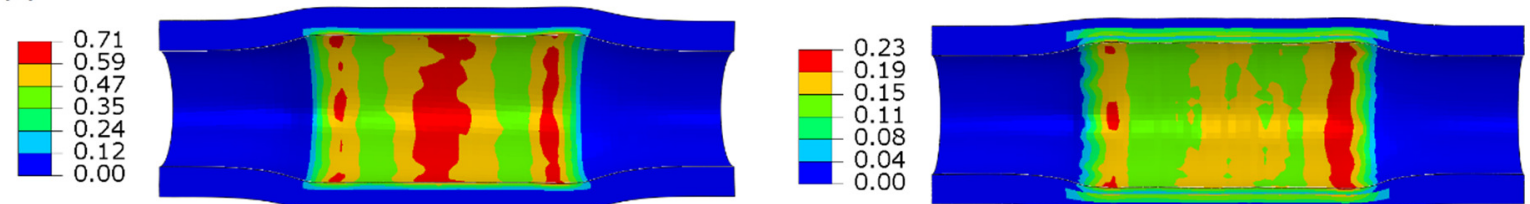

Figure 5. Contours plots of von Mises stress for (a) stent, (b) plaque and (c) artery after deployment of Xience stent, comparison between isotropic and anisotropic arterial models. 
(a)

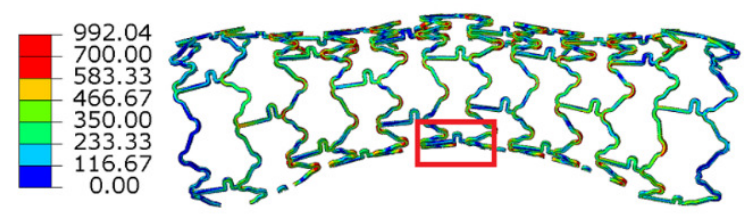

(b)

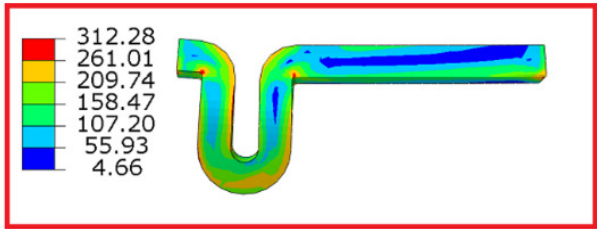

Without Residual Stress
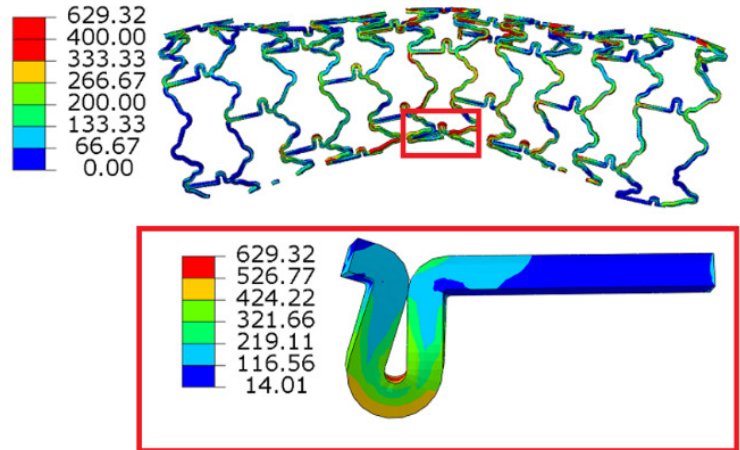

Figure 6. Comparison of deformation and von Mises stress for the stent simulated with and without considering residual stresses. 


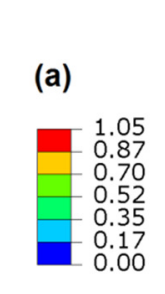

With Residual Stress

(a) $\begin{aligned} & \\ & \\ & -1.05 \\ & 0.87 \\ & 0.70 \\ & 0.52 \\ & 0.35 \\ & 0.17 \\ & 0.00\end{aligned}$
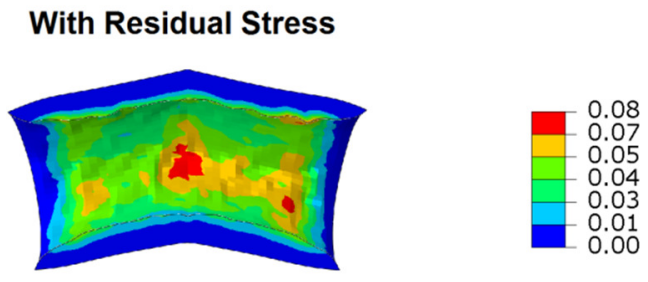

Without Residual Stress

(b)
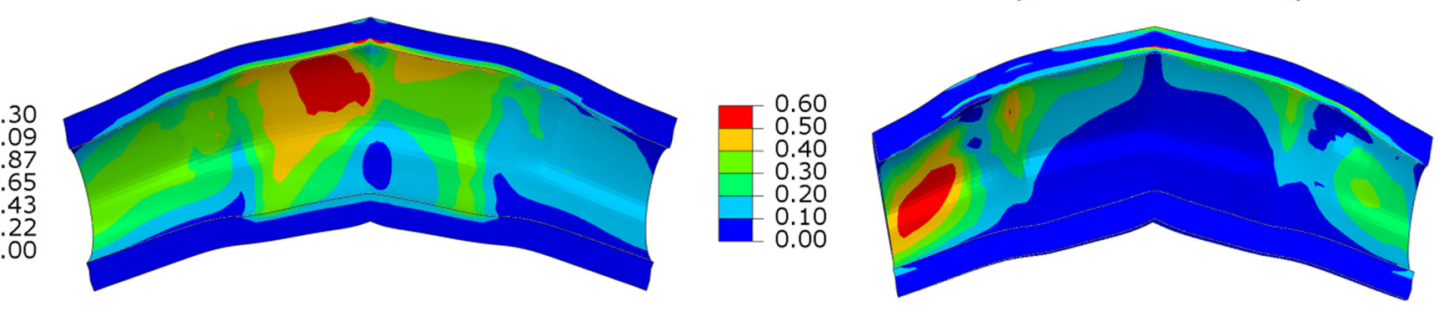

Figure 7. Contour plots of von Mises stress (a) on the plaque and (b) in the vessel layers after bending simulated with and without residual stresses. 
(a)

(b)
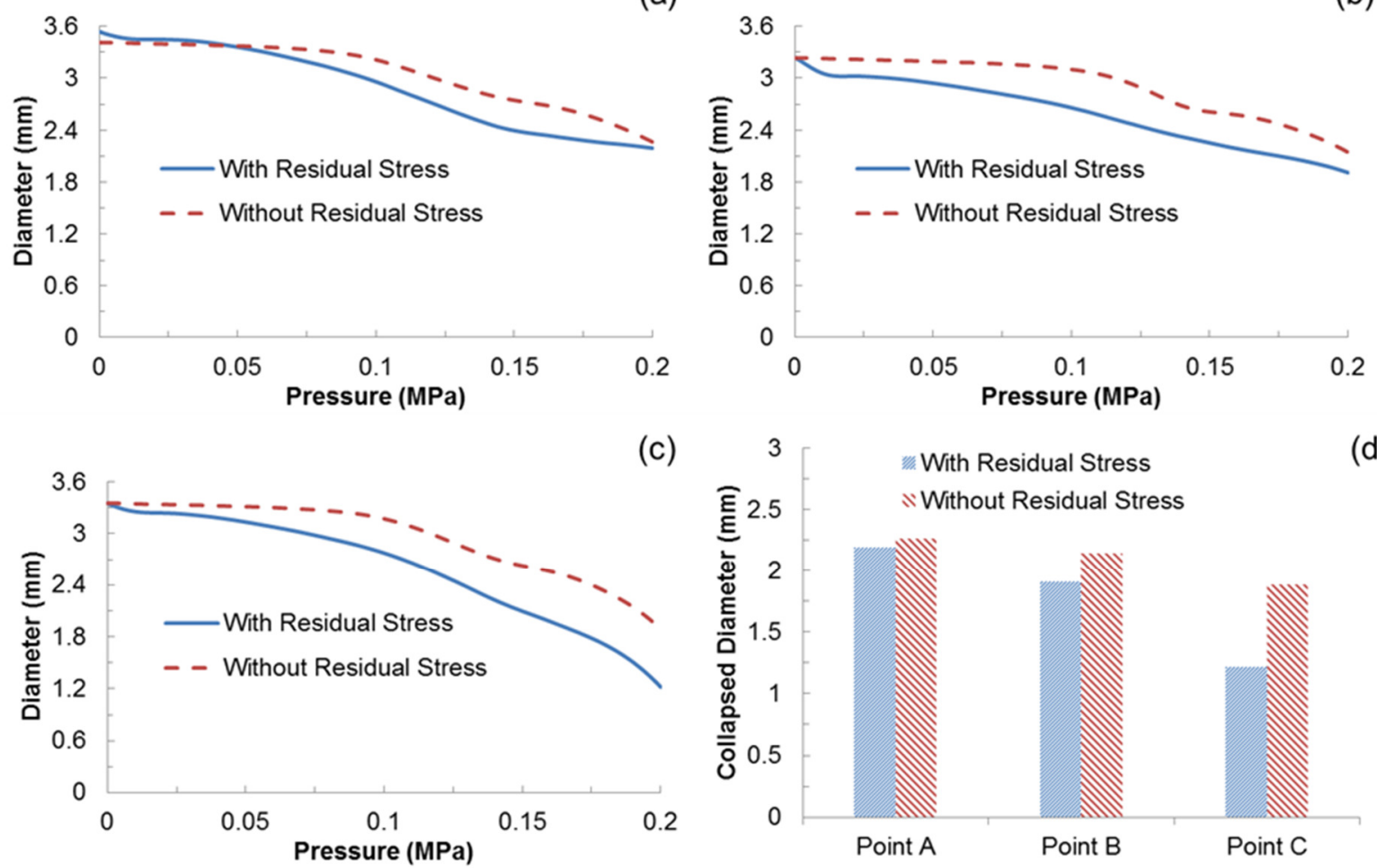

(d)

Figure 8. Diameter change against pressure during radial compression for (a) point A, (b) point B and (c) point C; (d) Comparison of collapsed diameters at maximum pressure $(0.2$ $\mathrm{MPa})$ for the three points. 
(a)
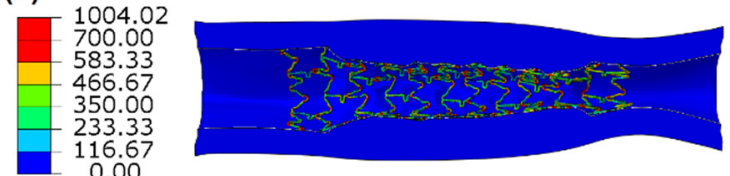

(b)
With Residual Stress

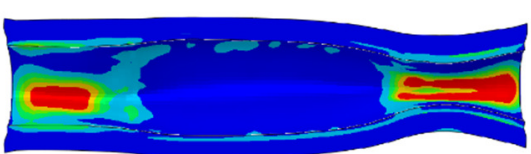

Without Residual Stress
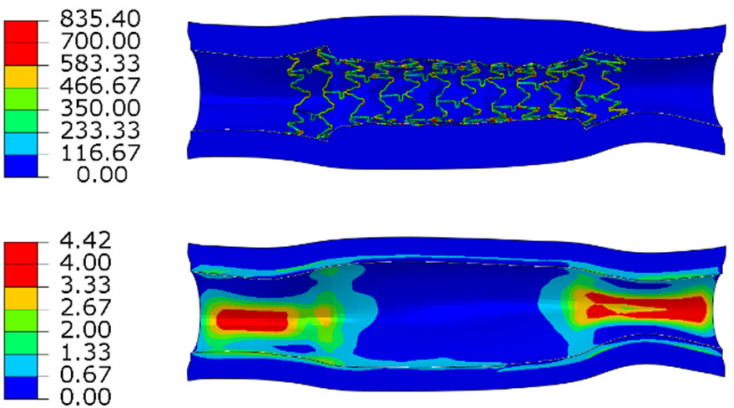

Figure 9. Contour plots of von Mises stress for (a) the stent and (b) the arterial wall at an applied pressure of $0.2 \mathrm{MPa}$ obtained from simulations with and without residual stresses. 

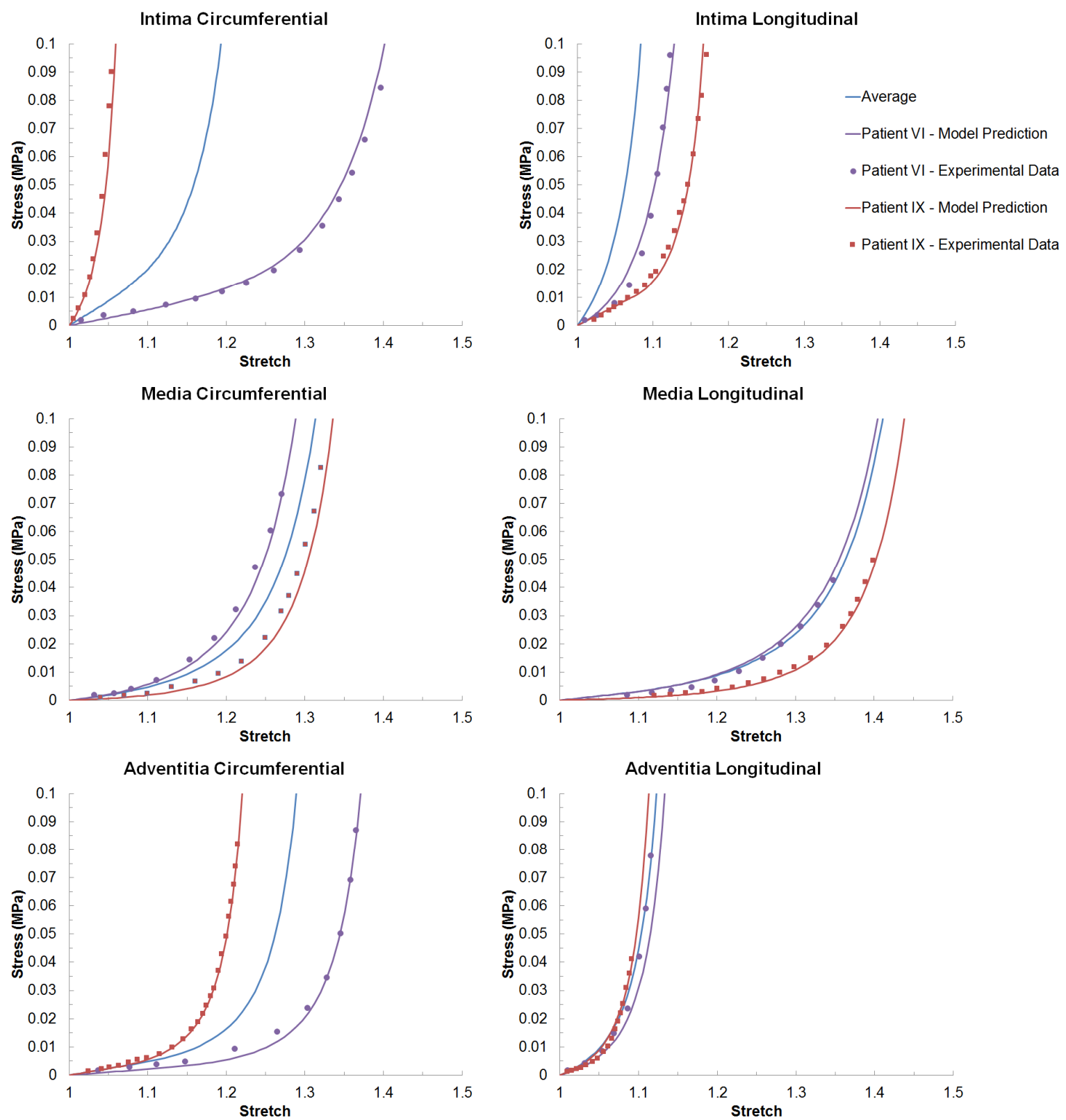

Figure 10. Stress-stretch response (HGO model vs experimental data) for patient VI and patient IX, in comparison with the average material behaviour. 


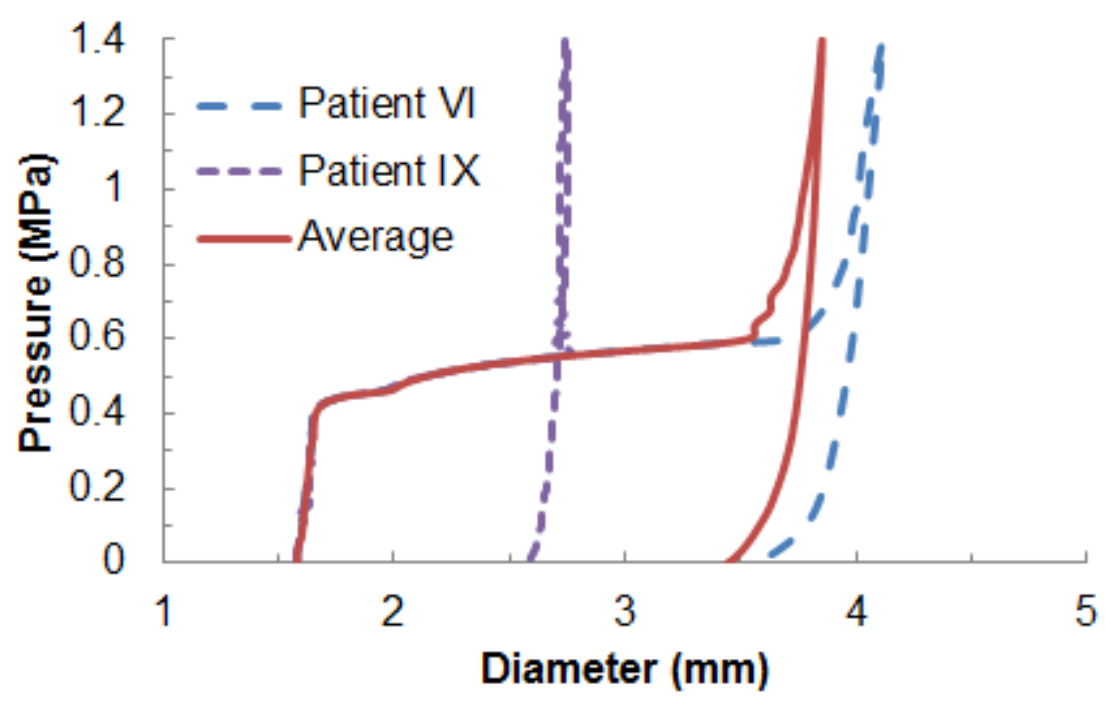

(a)

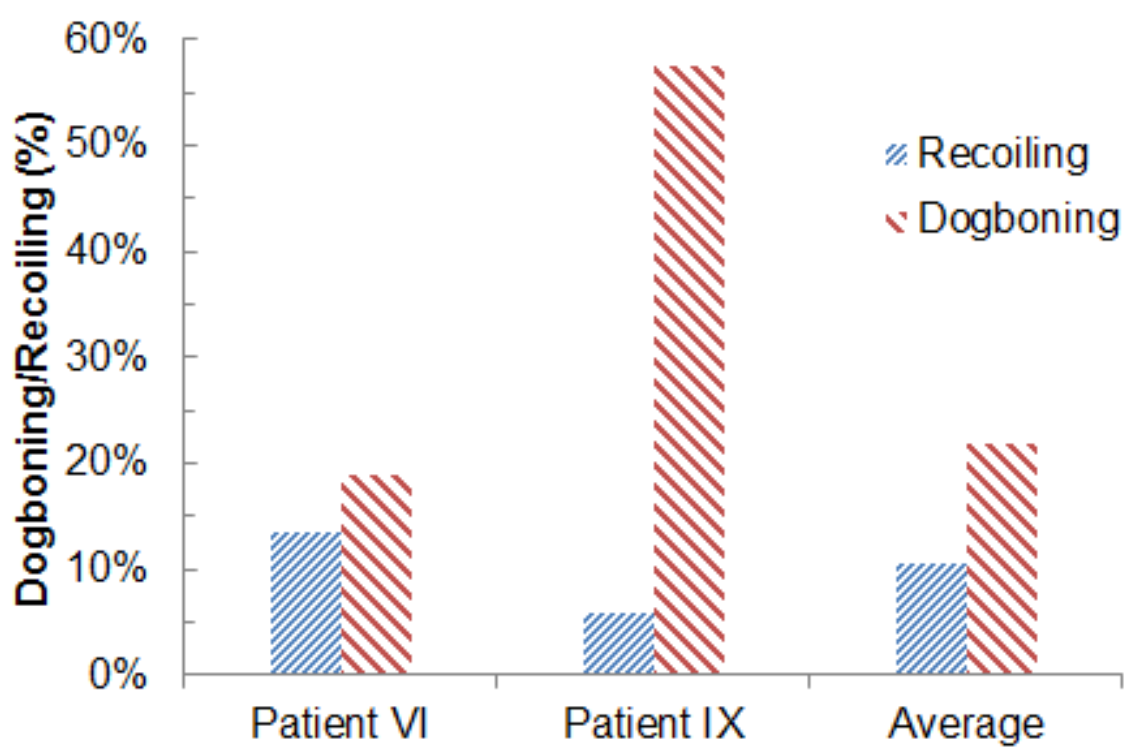

(b)

Figure 11. (a) Stent expansion and (b) recoiling and dogboning effects for the two specific patients, in comparison with those obtained from the mean artery behaviour. 
(a)

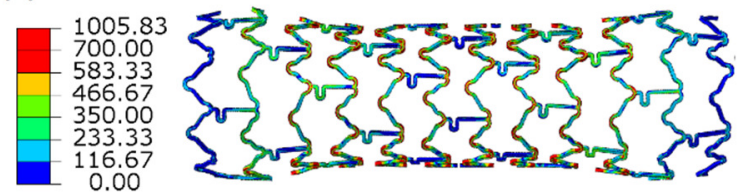

(b)

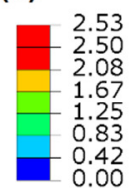

(c)
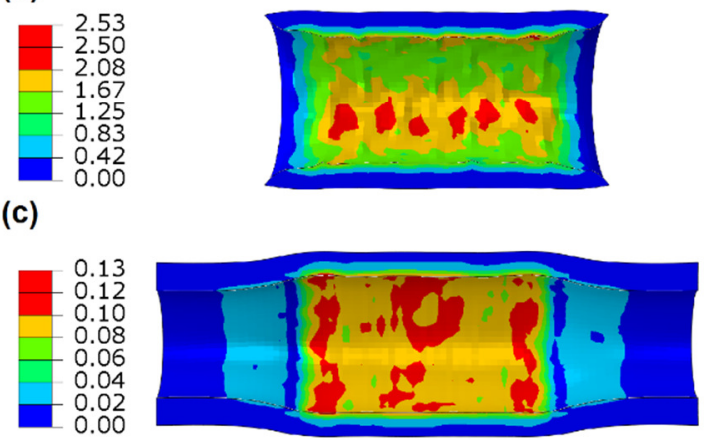

Patient IX
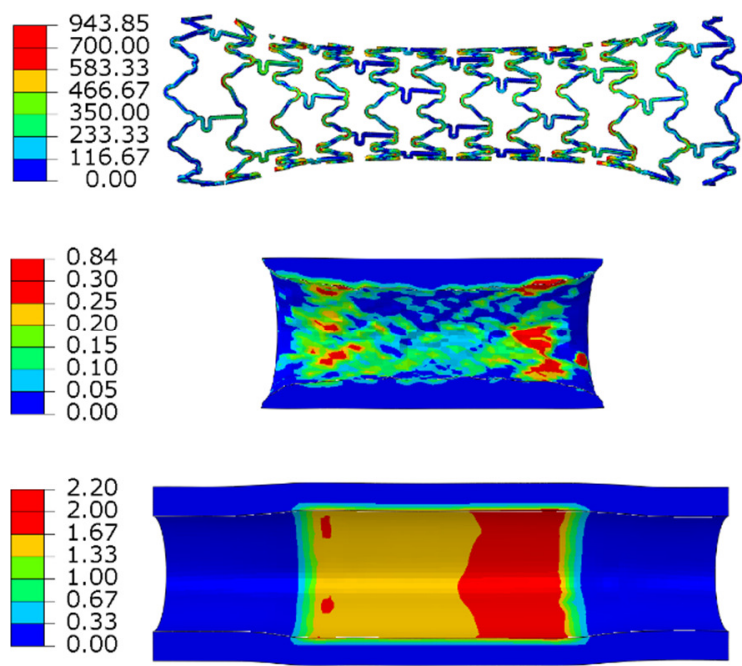

Figure 12. Contour plots of von Mises stress for (a) stent, (b) plaque and (c) arterial layers after deployment of Xience stent in arteries with patient specific behaviour (Holzapfel et al., 2005). 
Table 1. HGO model parameters fitted for the mean behaviour of each arterial layer (Holzapfel et al., 2005).

\begin{tabular}{lccccccc}
\hline Material & $\rho\left(\mathrm{kg} / \mathrm{mm}^{3}\right)$ & $C_{10}$ & $D$ & $k_{1}$ & $k_{2}$ & $\kappa$ & $\gamma$ \\
Intima & $1.066 \mathrm{E}-6$ & 0.03 & $8.95 \mathrm{E}-7$ & 4.0 & 1300.0 & 0.303 & $13.1^{\circ}$ \\
Media & $1.066 \mathrm{E}-6$ & 0.005 & $5.31 \mathrm{E}-6$ & 0.18 & 90.0 & 0.313 & $24.9^{\circ}$ \\
Adventitia & $1.066 \mathrm{E}-6$ & $8.32 \mathrm{E}-3$ & $4.67 \mathrm{E}-6$ & 1.0 & 800.0 & 0.298 & $75.3^{\circ}$ \\
& & & & & & & \\
\hline
\end{tabular}


Table 2. HGO model parameters for the arterial layers fitted for patients VI and IX (Holzapfel et al., 2005).

\begin{tabular}{|c|c|c|c|c|c|c|c|c|}
\hline & Material & $\rho\left(\mathrm{kg} / \mathrm{mm}^{3}\right)$ & $C_{10}$ & $D$ & $k_{1}$ & $k_{2}$ & $\kappa$ & $\gamma$ \\
\hline \multirow{3}{*}{ 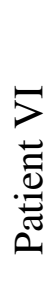 } & Intima & $1.066 \mathrm{E}-6$ & 0.01 & 8.95E-7 & 0.8 & 150 & 0.270 & $13.1^{\circ}$ \\
\hline & Media & $1.066 \mathrm{E}-6$ & $5.00 \mathrm{E}-3$ & $5.31 \mathrm{E}-6$ & 0.25 & 90 & 0.308 & $24.9^{\circ}$ \\
\hline & Adventitia & $1.066 \mathrm{E}-6$ & $4.00 \mathrm{E}-3$ & $4.67 \mathrm{E}-6$ & 0.5 & 500 & 0.285 & $75.3^{\circ}$ \\
\hline \multirow{3}{*}{ 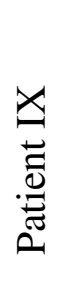 } & Intima & $1.066 \mathrm{E}-6$ & 0.023 & 8.95E-7 & 10 & 5000 & 0.308 & $13.1^{\circ}$ \\
\hline & Media & $1.066 \mathrm{E}-6$ & $1.40 \mathrm{E}-3$ & $5.31 \mathrm{E}-6$ & 0.1 & 100 & 0.313 & $24.9^{\circ}$ \\
\hline & Adventitia & $1.066 \mathrm{E}-6$ & 8.32E-3 & $4.67 \mathrm{E}-6$ & 1.6 & 1800 & 0.310 & $75.3^{\circ}$ \\
\hline
\end{tabular}

